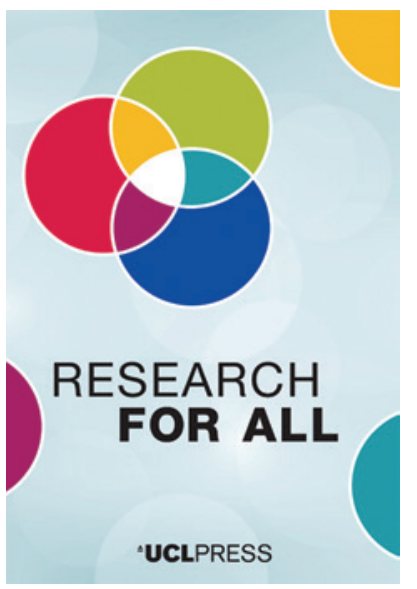

${ }^{\circledR}$ UCLPRESS

\section{RESEARCH FOR ALL}

The open-access journal for public engagement with research

ISSN 2399-8121 (Online)

Journal homepage:

https://www.uclpress.co.uk/pages/research-for-all

\title{
Co-producing research with academics and industry to create a more resilient UK water sector
}

Kate Baker (D, Sarah Ward iD, Briony Turner iD, James WebberiD, Chris Sweetapple (D, Peter Drake, David Thomas (D, Peter Melville-Shreeve (D, Guangtao Fu iD, Stephanie Cherington-Rimmell, Raziyeh Farmani iD and David ButleriD

\section{How to cite this article}

Baker, K., Ward, S., Turner, B., Webber, J., Sweetapple, C., Drake, P., Thomas, D., Melville-Shreeve, P., Fu, G., Cherington-Rimmell, S., Farmani, R. and Butler, D. (2020) 'Co-producing research with academics and industry to create a more resilient UK water sector'. Research for All, 4 (2), 150-68. Online. https://doi.org/10.14324/RFA.04.2.02

Submission date: 12 May 2019

Acceptance date: 26 May 2020

Publication date: 22 September 2020

\section{Peer review}

This article has been peer-reviewed through the journal's standard double-blind peer review, where both the reviewers and authors are anonymized during review.

\section{Copyright}

(c) 2020 Baker, Ward, Turner, Webber, Sweetapple, Drake, Thomas, Melville-Shreeve, Fu, Cherington-Rimmell, Farmani and Butler. This is an open-access article distributed under the terms of the Creative Commons Attribution Licence (CC BY) 4.0 https://creativecommons.org/ licenses/by/4.0/, which permits unrestricted use, distribution and reproduction in any medium, provided the original author and source are credited.

\section{Open access}

Research for All is a peer-reviewed open-access journal. 


\title{
Co-producing research with academics and industry to create a more resilient UK water sector
}

\author{
Kate Baker* - University of Exeter, UK \\ Sarah Ward - University of the West of England, UK \\ Briony Turner - National Centre for Earth Observation, Leicester, UK \\ James Webber - University of Exeter, UK \\ Chris Sweetapple - University of Exeter, UK \\ Peter Drake - Water Industry Forum, Huddersfield, UK \\ David Thomas - Scottish Water, UK \\ Peter Melville-Shreeve - University of Exeter, UK \\ Guangtao Fu - University of Exeter, UK \\ Stephanie Cherington-Rimmell - University of Exeter, UK \\ Raziyeh Farmani - University of Exeter, UK \\ David Butler - University of Exeter, UK
}

\begin{abstract}
Societal, economic and environmental impact generated by academic research is a key focus of publicly funded research in the UK. Drawing on experiences from the Safe \& SuRe project, a five-year research project that was co-produced with industry, this paper explores the challenges, learnings and benefits of coproducing research with academics and practitioners to create a more resilient UK water sector. Three aspects of the project are explored in detail: the use of a steering group, co-developing research intensively with a water company, and co-dissemination industry-facing events. Emerging themes include: (1) benefits of the industry steering group to develop working relationships and trust among the group; (2) increased dialogue and sharing of information between industry and academics going beyond the one-way communication more commonly reported by STEM academics; and (3) the value of co-disseminating research to maintain and engage new connections and spark new research questions.
\end{abstract}

Keywords: co-creation, co-dissemination, co-production, engagement, evaluation, water sector

Key messages

- Established Career Fellowships provide sufficient funds to support a whole team over an unusually long period of time for funded research. This enables midcareer academics to build their confidence to engage actors beyond academia, and to provide informal development opportunities in engagement for early career researchers.

- Steering groups for university-industry collaborations provide a forum for mutual learning that goes far beyond the one-way communication more commonly reported by STEM academics. 
- Organizing co-dissemination events with individuals and organizations who have an aligned vision and message saves time and financial investment. Specifically, collaboration across universities should be encouraged to improve organizational efficiency and aid internal networking.

\section{Introduction and background}

Over the past decade, the appetite for research impact, evidence-based policy and the knowledge economy has increased in the UK (Phillipson et al., 2012). The traditional 'one-way' mode of delivering information at the end of a research project has been shown to have limited impact and, instead, science is being steered towards becoming more collaborative and engaged (Jasanoff and Wynne, 1998; Lemos et al., 2018); this is referred to as 'co-production of knowledge'. Co-production of knowledge is defined as the process of producing usable or actionable science through collaboration between scientists and the managers or policymakers who use the science (Meadow et al., 2015). Research has shown that science that is co-produced with the users tends to have greater impact, as the users have a greater understanding of how the science is developed and they feel a sense of knowledge ownership (Jasanoff and Wynne, 1998; Wall et al., 2017).

Harding (2006) suggests that it is not helpful to see science as separate from local knowledges, cultures and politics, and decision making. Instead, research should take a more holistic approach, and from the beginning be co-produced with society, industry and government. The co-production of research requires effective collaboration between academics and industry partners, where reciprocal inputs produce useful research for both parties (Cherney, 2015). Universities can take the central role in serving as a hub for facilitating information exchange and pushing researchers to collaborate with stakeholders to solve societal-driven challenges (Trencher et al., 2014; Ward et al., 2018; Mader et al., 2013; Ferguson et al., 2018). In order for co-production to be successful, there is a need for research to focus on the practice of co-production to understand the challenges and to help improve practices (Gertner et al., 2011; Bjerregaard, 2010; Boardman and Ponomariov, 2009; Lemos et al., 2018).

Co-production should not be seen as the panacea for overcoming the many barriers of engaging academic research to stakeholders and publics, without recognizing its limitations and the problems that can arise during the process (Lemos et al., 2018). Even with a shared goal, successful collaboration and engagement is not instant, with partnerships taking time to develop (De Wit-de Vries et al., 2019). Stakeholders may have competing interests and strategies, which can make it difficult for everyone to align and collaborate (Dewulf et al., 2005; Sol et al., 2013). It can be a taxing process, with both researchers and stakeholders feeling that they do not have the skill set or personal inclination to participate (Lemos et al., 2018).

One way to improve the practice of co-production is to report and evaluate the process (Lemos et al., 2018). The sharing of experiences will enable the practice of co-production to be improved. This article reflects on the engagement strategy of a research project, Safe \& SuRe - a five-year $£ 1.5$ million Established Career Fellowship funded by the Engineering Physical Sciences Research Council (EPSRC) that was co-created and co-produced with industry to develop sustainable and resilient solutions for urban water management at a time of global uncertainty. We review the range of activities conducted with industry, from inception and co-production, 
to co-dissemination (see Figure 1). To frame these aspects, we tasked ourselves with answering three questions:

1) How do academics and industry benefit from working together?

2) What are the challenges and learnings from Safe \& SuRe working with industry?

3) How could the Safe \& SuRe co-production be improved?

The following section provides an overview of the Safe \& SuRe project, with information about engagement practices and people's roles in the project.

\section{Overview of Safe and SuRe and engagement activities}

The Safe \& SuRe fellowship was a five-year EPSRC-funded Established Career Fellowship awarded to Professor David Butler at the Centre for Water Systems, University of Exeter. The project resulted in over fifty publications; two spin-out companies; three decision support tools for industry; and contribution to five policy documents, including the development and writing of Ofwat's Resilience in the Round document (Ofwat, 2017), which aimed to direct investment across the water industry.

The project started in 2013, a time when the UK water sector was beginning to realize that the pre-twenty-first-century urban water systems were not sustainable or resilient enough to cope with future challenges. This shared goal helped align researchers and industry in developing a research project that was beneficial to both parties. The fellowship had a dedicated research team, which included one principal investigator (PI), Professor David Butler, and three academic co-investigators, and it co-funded eight postdoctoral research fellows and associated PhD students. At the end of the fellowship, the Safe \& SuRe team obtained an EPSRC Impact Acceleration Account Impact Award. This funded two research fellows for an additional six months and enabled them to work intensively with Scottish Water to co-develop aspects of the Safe \& SuRe project.

Figure 1: Overview of the main co-production activities discussed in this paper

\section{Industry steering group}

- 12 active steering group members over the five-year project.

- Two meetings annually, each lasting one day. The format of the steering group would include a morning of presentations followed by an afternoon of interactive workshops or group activities.

- In between the steering group meetings there would be online communication between individuals working on specific projects.

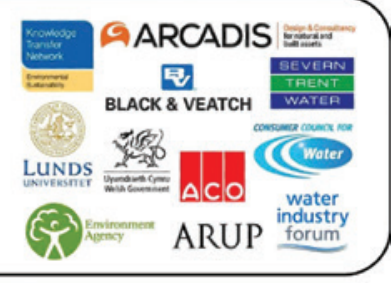

\section{Intensive co-development}

- At the end of the project an EPSRC Impact Acceleration Account Impact Award was awarded to co-develop two main outputs with the statutory corporation that provides water and sewerage services across Scotland, Scottish Water.

- This award enabled an extra six months to be added onto the end of Trusted to serve Scotland the Safe \& SuRe project which funded two research fellows.

\section{Co-disseminate industry-facing events}

- Co-produce events with industry. Two case studies are reviewed in this paper. The first event was with the Water Industry Forum on resilience for the water sector.

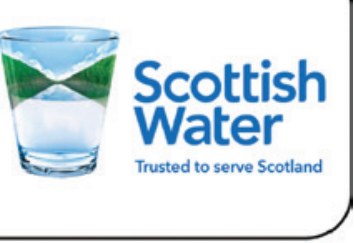

- The second event was a collaboration with the Global Advancement team at the University of Exeter to host a showcase evening with the aim of engaging the Safe \& SuRe fellowship with a wider audience.

water

industry

forum 
The engagement strategy was developed during the fellowship application. It included communication activities such as a website (www.safeandsure.info), social media and conferences, plus co-production activities, including an industry steering group and co-dissemination events and workshops with industry. The intensive six-month codevelopment period with Scottish Water was added during the project. Figure 1 highlights the main co-production activities that are discussed in this paper.

Steering groups are common practice in a range of areas and sectors, and they provide a group of people who are experts on a topic to oversee a project, and to provide advice and troubleshoot where necessary. The aim of the Safe \& SuRe steering group was to co-produce research with water sector experts so that the work would have a positive impact on industry and policy. The industry steering group included a range of practitioners and policymakers, including: three water companies - Northumbrian Water, Severn Trent Water and Welsh Water; five engineering consultancies - ACO, Arcadis, Arup, Black \& Veatch, and Water Policy International; the Water Industry Forum, a not-for-profit stakeholder forum; the Environment Agency; the Consumer Council for Water, a statutory consumer body for the water industry in England and Wales; the Environmental Sustainability Knowledge Transfer Network; and Lund University, Sweden. There were no community groups or non-governmental organizations (NGOs) on the steering group. Researchers met with the steering group twice a year, and had online communication between meetings.

The co-development period with Scottish Water was initiated after Scottish Water learnt about the Safe \& SuRe project at an industry conference at the beginning of 2017. Synergies and links were made between the Safe \& SuRe project and Scottish Water's work. After a string of successful meetings, which included multiple stakeholders (strategy, asset planning, operations), it was decided that the development of the Safe \& SuRe Resilience Framework was a way to collaborate. The Safe \& SuRe framework underpinned Scottish Water's understanding of how the resilience concept applied to wastewater systems. They wanted to adapt this framework into an interactive tool as a means to explore and communicate the resilience concept at multiple scales and to multiple stakeholders. This would be helpful to practitioners and decision makers to enable informed choices to be made to benefit the sector in the present and the future.

The Safe \& SuRe research team used co-dissemination events. First, they worked with the Global Advancement team at the University of Exeter to organize an evening showcase and networking event in London. The aim of this for Safe \& SuRe was to access the university's established alumni network within the water sector, while the Global Advancement team wanted to engage alumni with current research being conducted. The second event was an end-of-project event in the form of a one-day symposium on the topic of resilience, organized with the Water Industry Forum (WIF). WIF is a not-for-profit forum that brings together different stakeholders from across the UK water sector. The Safe \& SuRe team wanted to work with WIF as they have extensive networks in the water sector and, after discussion with the industry steering group, it was decided that a more diverse audience would attend the symposium if it was co-disseminated with industry.

\section{Methods}

The project had an associated stakeholder engagement strategy, which was developed through the 'Pathways to Impact' document. There was no evaluation process locked into place before the project commenced. Therefore, this review is predominantly 
descriptive, based upon case study reviews and reflections taken from interviews, a focus group and a questionnaire to investigate the benefits and challenges of the Safe \& SuRe knowledge exchange strategy. The paper focuses on the three main co-production activities outlined in Figure 1: industry steering group, intensive codevelopment of Safe \& SuRe research with Scottish Water, and co-disseminating with industry. Table 1 gives an overview of the evaluation techniques and personnel involved within each component of the project, which is followed by a brief overview of evaluation techniques used. As this paper is written by people who were actively involved in the Safe \& SuRe project, Briony Turner, Climate Services Development Manager at Space4Climate, was asked to reflect and comment. Briony has more than ten years' experience of bridging the gap between academic research, policy and professional practice. Briony is familiar with the Safe \& SuRe fellowship, as she was invited to run a stakeholder mapping workshop in 2017. Briony provides her reflections on the delivery of industry engagement activities in Box 1.

- Principal investigator: A semi-structured interview was conducted with the PI, Professor David Butler. The PI was asked to reflect on the main driver for cocreating the fellowship with industry, the benefits of co-creating a research project with industry, the challenges and the learnings of how to improve the engagement strategy. The interview lasted approximately one hour and was recorded and transcribed.

\begin{tabular}{|c|c|c|c|}
\hline $\begin{array}{l}\text { Project structure } \\
\text { component }\end{array}$ & $\begin{array}{l}\text { Number of } \\
\text { personnel }\end{array}$ & $\begin{array}{l}\text { Number of } \\
\text { organizations }\end{array}$ & Evaluation techniques applied \\
\hline $\begin{array}{l}\text { Project and academic } \\
\text { leadership }\end{array}$ & 4 & 1 & $\begin{array}{l}1 \text { semi-structured interview with } \mathrm{PI} \\
3 \text { email and verbal feedback with } \\
\text { the co-Pls }\end{array}$ \\
\hline $\begin{array}{l}\text { Research team excluding } \\
\text { senior academic leaders } \\
\text { (PhD and postdoctoral } \\
\text { researchers) }\end{array}$ & 7 & 1 & $\begin{array}{l}\text { Focus group with } 7 \text { of the } \\
\text { researchers - used instead of } \\
\text { individual interviews as it was a } \\
\text { productive way to pool ideas and } \\
\text { discuss some of the themes as a } \\
\text { group }\end{array}$ \\
\hline $\begin{array}{l}\text { Industry steering group, } \\
\text { which includes } 12 \text { active } \\
\text { organizations (listed in } \\
\text { text) }\end{array}$ & 12 & 12 & $\begin{array}{l}\text { Questionnaire distributed by } \\
\text { email with option to respond } \\
\text { anonymously. Two organizations } \\
\text { requested to remain anonymous }\end{array}$ \\
\hline $\begin{array}{l}\text { Engagement activity } \\
\text { partners: } \\
\text { University } \\
\text { Water Industry Forum } \\
\text { \& University of Exeter } \\
\text { Global Advancement } \\
\text { Team }\end{array}$ & 2 & 2 & $\begin{array}{l}2 \text { semi-structured interviews, } \\
\text { with a representative from each } \\
\text { partnering organization }\end{array}$ \\
\hline $\begin{array}{l}\text { Intensive co-development } \\
\text { of research outputs with } \\
\text { Scottish Water }\end{array}$ & 1 & 1 & $\begin{array}{l}\text { Email feedback, phone discussion } \\
\text { and co-writing }\end{array}$ \\
\hline $\begin{array}{l}\text { External reviewers: Briony } \\
\text { Turner }\end{array}$ & 1 & 1 & Email feedback \\
\hline
\end{tabular}


Box 1: Briony Turner's reflections on Safe \& SuRe

Before launching into a reflection, it is important to acknowledge the achievements of the research team in delivering research outcomes that were evidently deployed within industry practice.

The feedback generated on the project's co-production activities indicated a variety of skills developed, honed and acknowledged as beneficial among all involved. From enabling spaces for critical thinking, reflection and formation of new ideas, to active listening, it appears that the performance of participation has engendered a loosening of explicit and tacit organizational boundaries. The example of Scottish Water illustrates how mechanisms to embed researchers within industry enabled new assemblages of capability and expertise, as well as pathways for implementation of novel analytics, to emerge.

For a project based on water, a fundamental human right, there was an interesting absence of instances of conflict. Perhaps it is easier to co-produce research when the stakeholder and researcher values are aligned by an objective with societal benefit, in this case, a resilient water sector. As Tara Fenwick (2016) raises in her book on professional responsibility and professionalism, care needs to be taken to consider how social responsibility is governed, and how the boundaries are set and evolve when it comes to professional accountability - be they from the research, industry or policy community - for complex, deep systemic problems.

I therefore feel it is important to point out that the project's engagement activities were framed by a 'Pathway to Impact' plan, an essential component of any EPSRC-funded fellowship proposal until March 2020. Given the reflections of the Safe \& SuRe researchers on the skills they developed as a result of the co-production process, it is interesting to note that UK Research and Innovation has subsequently removed the onus of requiring impact planning, recognizing instead the importance of providing a stronger supportive environment for realization of (research) potential (UKRI, 2020).

From my experience of reviewing impact plans, they tended to opt for form over process. Engagement structures proposed would often mirror corporate organizational structures, for example, an advisory board or, as with this project, a steering group. That is why I find the learning point particularly interesting on the recognition by the researchers of the need, but absence of action, to engage NGOs and the public. Had there been a processdriven rather than form-driven approach to stakeholder engagement, might this have been identified earlier?

When I conducted the stakeholder mapping workshop with the researchers four years into the project, these engagement gaps were identified, and it was evident within the combined personal stakeholder networks of the research team that strong enough links existed to pursue targeted engagement and dissemination activity. My feeling is that this collective stakeholder network of the individual researchers remained in the shadows, unconsciously sidelined by the strong formalized hierarchical governance structure, which reinforced research activity complicit with governance structures and professional practices, rather than leaving them open for scrutiny.

Finally, I would like to turn to challenges identified by some of the researchers in understanding and aligning to industry key performance indicators and time frames. Such mechanisms used in corporate practice are designed towards individual accountability and benefit. They work through time frames and targets that, by their very nature, can push out time for both critical thinking and empowerment to integrate niche activity into mainstream practice. There was no questioning or reflection on the expectation that researchers would equip themselves with engagement capability, and learn to communicate in a manner that aligned with normative industry practice. Yet, by doing so, those very working practices were performed and normalized by the researchers, rendered invisible as a potential topic of enquiry of the Safe \& SuRe research.

I am left contemplating whether successful research co-production might inhibit both the questioning of professional knowledge structures, accountability and practice, and the development of new forms of knowledge mobilization.

- Researchers: A one-hour focus group was conducted with the Safe \& SuRe researchers. This included PhD researchers and postdoctoral researchers, with feedback taken from seven researchers in total. A focus group was used instead of 
individual interviews as it was a productive way to pool ideas and discuss some of the themes as a group.

- Industry steering group: An online questionnaire was sent to all members of the industry steering group; 10 of the 12 active steering group members filled in the questionnaire. A questionnaire was used instead of individual interviews or a focus group due to logistics, as the steering group hold senior positions and are situated across the UK. The research team wanted to make it as easy as possible for them to contribute to this paper. The questionnaire focused on the drivers for their engagement with the Safe \& SuRe fellowship, the benefits and challenges from being on the steering group, and how the knowledge exchange strategy could be improved.

- Partnering organizations: The Safe \& SuRe team held co-dissemination events with other organizations and departments within the university. A semi-structured interview was conducted with Stephanie Cherington-Rimmell, Senior Development Manager within the Global Advancement team, and Peter Drake, CEO of the Water Industry Forum. Both event partners were asked what their main driver was for working with the Safe \& SuRe team, and what the benefits, challenges and learnings were. Both interviews lasted approximately twenty minutes, and they were recorded and transcribed.

- Scottish Water: Multiple stakeholders at all levels of management within Scottish Water were engaged through multiple meetings and workshops. David Thomas, Strategic Planner in the Wastewater Resilience Team at Scottish Water, used this information to co-write the section on co-developing Safe \& SuRe findings for use within Scottish Water.

\section{Results}

Results are split into three sections: the first is on the industry steering group, the second is on co-development of research outputs with Scottish Water, and the third is on co-dissemination of research through a review of two case studies of industry-facing events. Within these subsections, we directly answer the questions we posed in the Introduction and Background section of this paper.

\section{Industry steering group}

The principal investigator highlighted that a benefit of having an industry steering group is that researchers have an established group of 'experts' from multidisciplinary backgrounds with a strong understanding of the project, making it easier to build relationships. This generates informal mentorship for researchers, which can be powerful as it helps to develop well-rounded researchers and provides new opportunities during and after the research project. The principal investigator also noted that it takes time to build up these networks and to build trust, so the group is especially helpful for students and early career researchers.

Researchers on the Safe \& SuRe project highlighted three main benefits of having the industry steering group: accessing an established network of industry 'experts', broadening research perspectives, and improving interdisciplinary communication skills (see Figure 2). Researchers said that the interactions with industry helped to challenge their perceptions, providing new perspectives on solving problems and stimulating ideas. Time was dedicated to interactive activities, which helped to build relationships, and for groups to focus on specific issues (see Figures $3 a$ and $3 b$ ). 
Figure 2: Review of the steering group with benefits and learnings of industry and academics working together

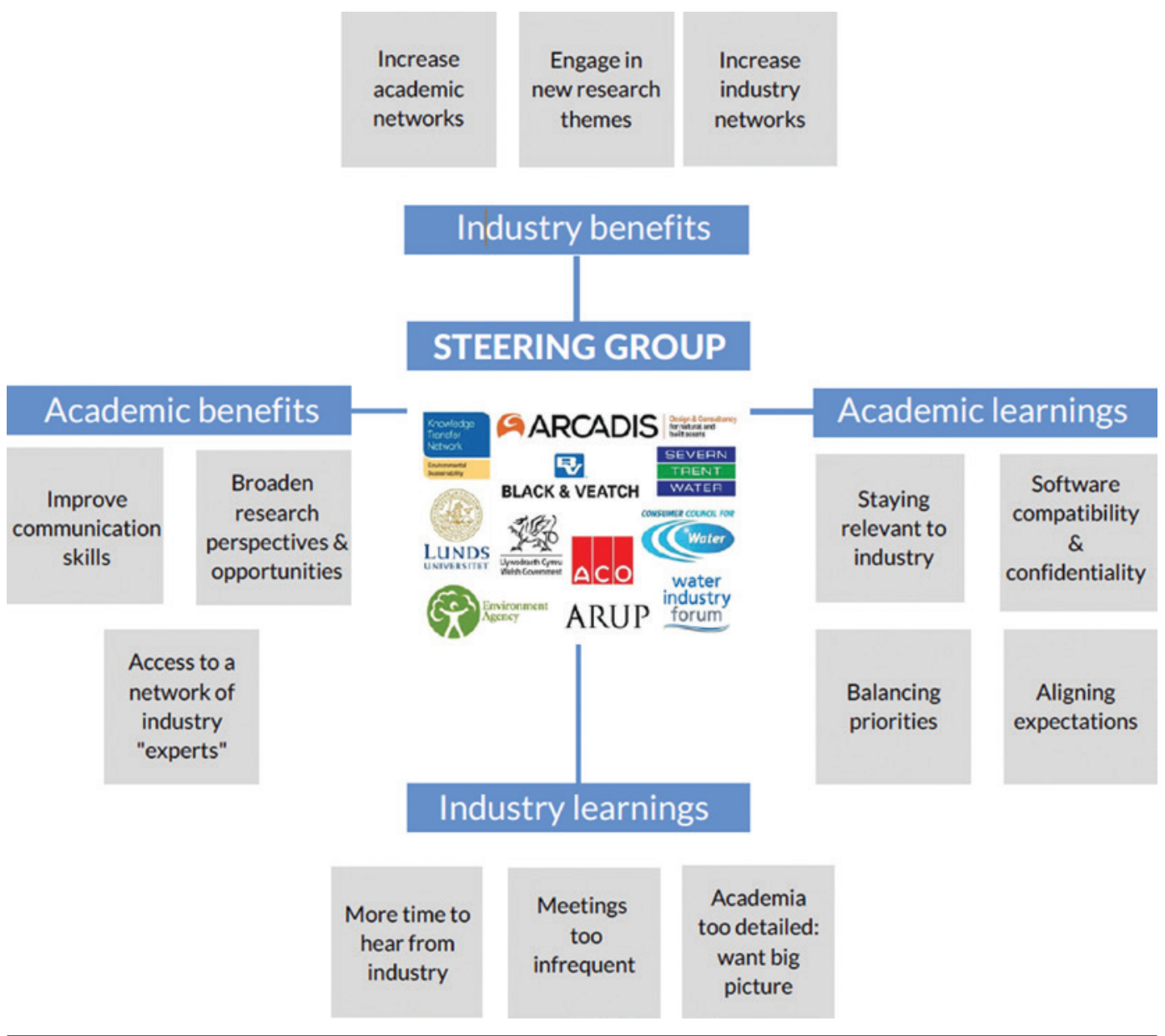

The consistent contact with the industry steering group kept the research on track towards practical applicability in the real world, and helped researchers learn how to communicate to different audiences.

Working with industry helped academics to identify knowledge gaps and potential applications of their work in industry. One such example is the development of OTA Analytics, a Safe \& SuRe spin-out company, which provides real-time control solutions for utilities, commercial customers and domestic installations. Founder Dr Peter MelvilleShreeve undertook his engineering doctorate in collaboration with Severn Trent Water, as part of the Safe \& SuRe project. Dr Melville-Shreeve explains how having the support from the steering group, and specifically Severn Trent, helped to build the company: 'The sheer scale of the Severn Trent Water network, along with the go-forwards attitude of the innovation team helped OTA Analytics build a business plan and identify an investor partner in the form of a leading water infrastructure company.'

The steering group benefited from being involved in the Safe \& SuRe project (see Figure 2). The majority of the steering group (eight out of the ten members) found that it increased their academic networks, and seven out of ten said that it increased their industry networks. Being part of the steering group created a space for academics and industry to come together, and because the project lasted for five years, it enabled relationships to build and trust to develop. Over the lifetime of the project, the topic of resilience moved up the political and regulatory agenda and, therefore, members 
Figure 3: Steering group meetings were a space to share ideas through exercises such as mind mapping (a), and where researchers and industry could work together on a specific issue, which was then shared with the wider group (b)
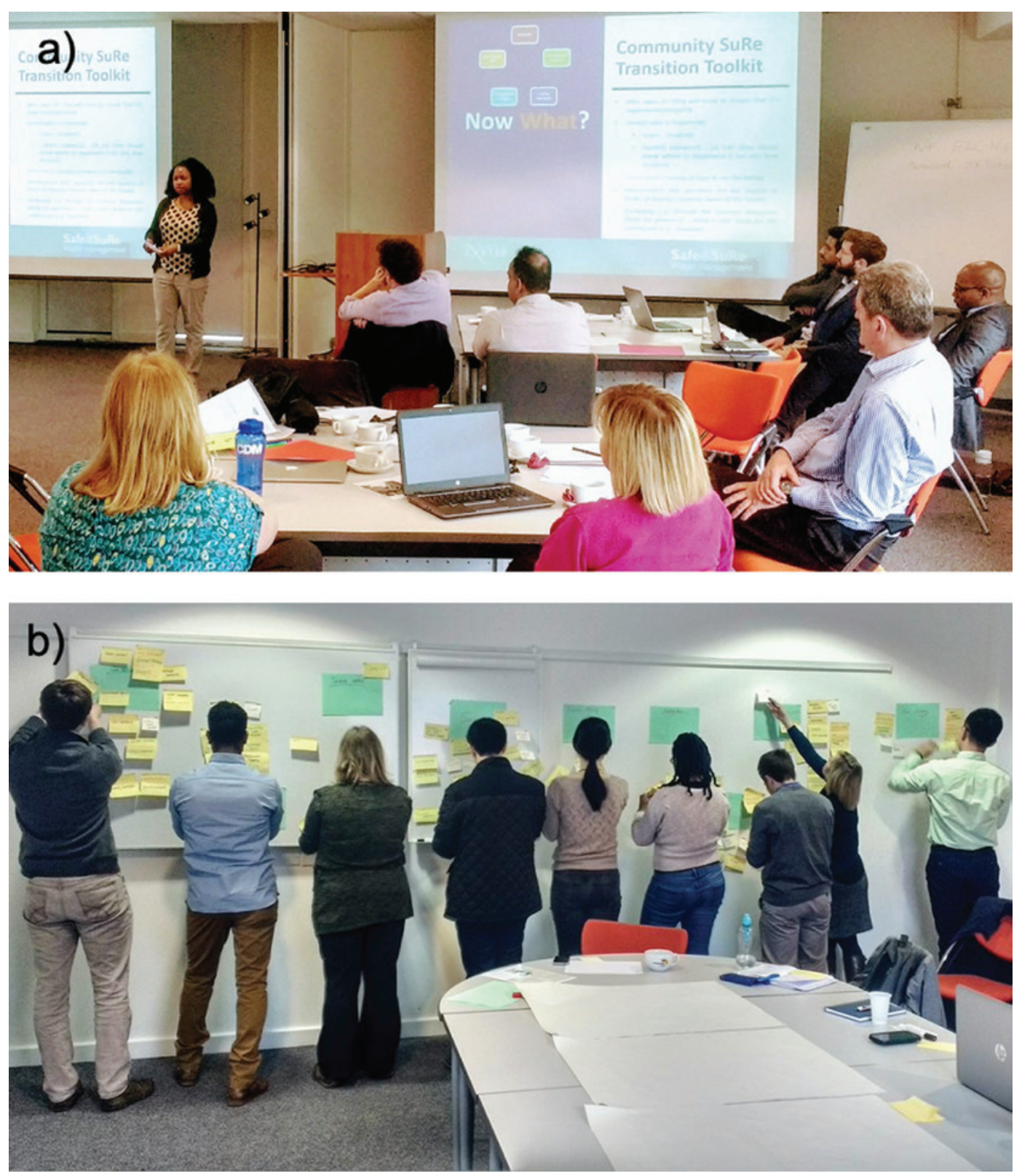

found it very beneficial to be at the forefront of academic developments. Over half of the steering group (seven out of the ten members) noted that the opportunity to be involved in progressive research was a benefit. One member of the steering group, who worked closely with a PhD researcher to develop a decision support tool (Webber et al., 2019)، said that an unexpected benefit was the potential for collaborations with academics.

As with any collaboration, there are always challenges and learnings. For researchers, four main challenges arose: staying relevant to industry, aligning expectations, balancing priorities, and issues around software compatibility and confidentiality issues (see Figure 2). The first challenge of staying relevant to the industry steering group was sometimes difficult due to different perceptions of style, metrics of success, and timescales between academia and industry. There was also concern about who was on the steering group (being mainly water companies and consultancies). 
A PhD student, who had worked with local community groups through their research, said that engagement should extend beyond industry 'experts' and perhaps include other specific stakeholders relevant to Safe \& SuRe research: 'They may not be policymakers, but if they are engaged in an activity related to our research then it provides an opportunity for co-learning and co-creating outputs.'

Researchers discussed that the Safe \& SuRe project outputs might have looked different if those groups had been part of the Safe \& SuRe engagement strategy and involved in the steering group. The PI was also aware that the steering group did not contain NGOs or community groups, and agreed that this was something that, with hindsight, could have been improved.

The second challenge was aligning expectations when academia and industry work on different timescales. Researchers found it hard to manage workload with conflicting deadlines and additional approval from industry. The PI noted that: 'It can be tricky to manage stakeholder expectation. For example, what's going to be achieved, on what timescale, what can they walk away with and use tomorrow?'

The third challenge highlighted by academics was balancing priorities. Some researchers on the Safe \& SuRe project explained how co-producing research with industry left less time for academic outputs. Although co-production is promoted by academic institutions, when academics go for promotion, institutions are mainly interested in academic publications and funding history. The fourth and final challenge from the academics was the need to balance expectations around software compatibility and confidentiality. Researchers want to publish the results, as they are rewarded by the number and quality of publications, whereas industry wants to keep the knowledge a secret to provide a competitive advantage.

The industry steering group highlighted similar challenges and learnings (see Figure 2). First, the different timescales in industry and academia. Four out of the ten steering group members said that the different timescales and processes in industry and academia created a challenge, and made it difficult for both sides to align. This can make it difficult when industry is involved in the planning, as industry works on different, often quicker, timescales. One industry member who had been involved in a funding bid to continue the translation of the Safe \& SuRe fellowship was disappointed that a bespoke translation project with their company would not happen due to the funding bid being unsuccessful: 'We were hoping that the Fellowship with Exeter could have facilitated bringing in the learning into our company - however, the first application has not been successful.'

The second challenge and learning point that was highlighted by the steering group was that the meetings were too infrequent, with little information in between the sessions. The most popular suggestions for improving communication were having updates in between the sessions via email (seven out of the ten steering group members) or having a newsletter (five out of the ten steering group members). Other suggestions by the steering group included homework and/or short briefing packs for the members: 'Pre-meeting preparation (homework) to make best use of the time available on the day, and to help board members reacquaint themselves with the themes, such that they are already thinking about the issues before arriving.'

The third challenge and learning point from the steering group was how the industry steering group meetings focused on sharing research from the Safe \& SuRe project, with little or no time to hear about what the individual members of the industry steering group were doing. Creating more of a space for industry to share their work could help further align interests. One steering group member thought that aspects of Safe \& SuRe research were 'trailing industry best practice', 
and it was suggested that a best practice review session early on in the research programme could have avoided this.

\section{Intensive co-development of Safe \& SuRe research with Scottish Water}

The six-month co-development of the Safe \& SuRe framework from a diagram (see Figure $4 a$ ) into an interactive tool (see Figures $4 b$ and $4 c$ ) to assist the wastewater strategy team in Scottish Water to build resilience in a holistic manner was seen as a success by all involved. Scottish Water reported that the framework tool provides a platform to engage conversations around resilience, and a means of recording discussions. It enables users to understand the definition of resilience, how it applies within the context of a project or strategy, and how interventions can enhance resilience practically. Scottish Water have found the tool to be helpful in communicating the strategic objectives of the resilience strategy, and its goal of future-proofing service, to all business functions.

A key element of the successful partnership was establishing regular written and verbal communication, despite the challenges of remote working. This was facilitated by both parties being committed to communication, and responding to queries and requests in a timely manner. This online communication was strengthened by three face-to-face meetings to further enhance the working relationship. Working with Scottish Water enabled the Safe \& SuRe research fellows to better understand the pressures and challenges facing the water sector. Specifically, it enabled a greater understanding of how their research can translate and be applied within the strategic planning sector of a water company. A Safe \& SuRe research fellow noted: 'Good communication throughout the six months meant that we knew what we needed to focus on to make sure the tool could be integrated [with Scottish Water's existing procedures] and would be adopted.'

For the lead employee of Scottish Water, it highlighted how academic research can benefit industry's approach to resilience:

The Safe \& SuRe framework has been fundamental in underpinning our application of the resilience concept to the wastewater system. Translating

Figure 4: (a) The Safe \& SuRe interventions framework applied to the threat of increasing urbanization; (b) home page of the Safe \& SuRe decision support tool; with (c) an illustration of the analysis component

a)

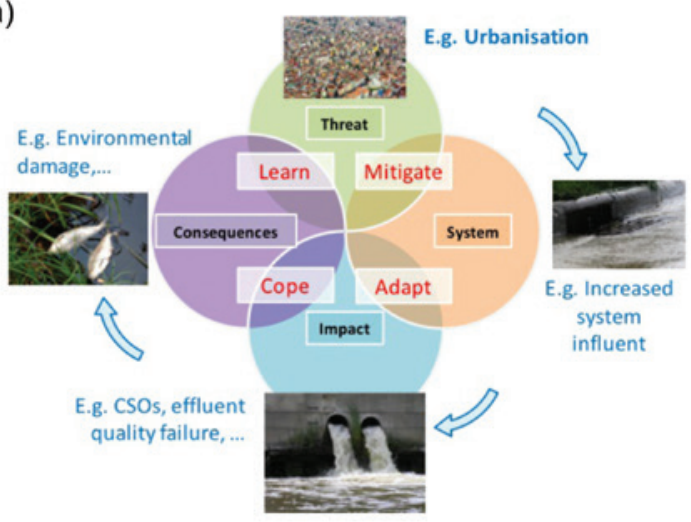

b)

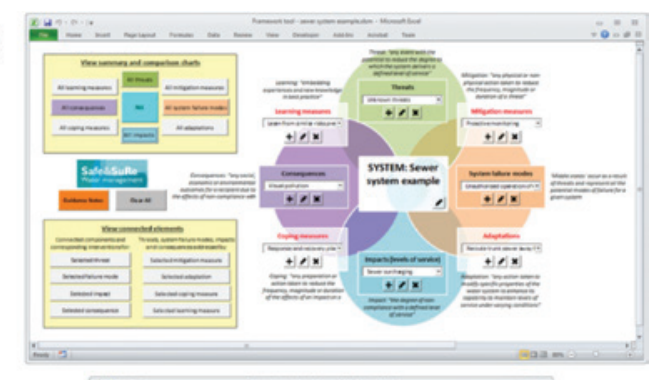

c)

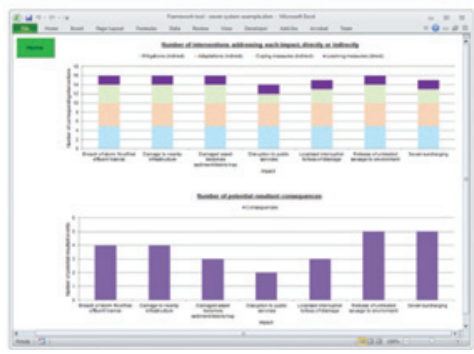


this academic research into an interactive tool will enable resilience thinking to be integrated within multiple business functions. The key benefits so far have been the ease of communicating the resilience concept to all users, and the demonstration of the multiple benefits of resilience enhancement interventions.

The collaboration improved understanding of the resilience concept, and provided a basis for the strategies that are being developed for baselining and enhancing the resilience of Scottish Water's wastewater systems. Due to this positive experience, the employee from Scottish Water noted that they would actively seek out future collaboration opportunities with academic institutions. In addition, an agreed learning point was to set metrics at the beginning of collaborations to measure and define success.

\section{Industry-facing co-dissemination events}

The Safe \& SuRe team worked internally across departments and externally to organize events. Ideas for events often came about through conversations that revealed alignment and overlap in terms of what the event needed to include, and by adjusting ideas at the beginning, it was possible to co-create something that was beneficial to both. The Safe \& SuRe team worked internally with the Global Advancement team at the University of Exeter, who build long-term relationships with the university's alumni and other supporters around the world. While researchers wished to extend the project's industry network, the aim for the Global Advancement team was to engage 'hard to reach' alumni graduates from water engineering.

Stephanie Cherington-Rimmell (Senior Development Manager in the Global Advancement team) explained that engaging alumni in current research is more effective when academics communicate their work in person and make an effort to relate it to the audience: 'The real benefit of working with Safe \& SuRe is that they are already working with industry experts, so they know what is going to be appealing and topical.'

The advantage of Safe \& SuRe working with the Global Advancement team is that they frequently host events and have the systems in place to organize events that are attractive to a diverse audience. The researchers learnt from these experienced event organizers: for example, the event needed to be in a convenient location with the right hooks to get people to attend. After brainstorming ideas, it was decided that conventional presentations would be banned and, instead, researchers had to be creative with large visuals and interactive games to engage industry. Most importantly, through the Global Advancement team, Safe \& SuRe were able to access a new community of people who are already linked to the university and, therefore, easier and quicker to engage. There is a video of the event here: www.youtube.com/ watch? $v=$ coqQxzZixmU.

The second event was organized with the Water Industry Forum (WIF). They were keen to work with Safe \& SuRe, as the topic of resilience was current and relevant to the water industry. The CEO of WIF, Peter Drake, said: '[Resilience] is very relevant to the water industry, it still poses significant challenges and is something that Safe \& SuRe have something to say, so should be given a platform to say it.'

Creating and organizing the event together meant that it saved money and time on both sides, plus by sharing ideas, a more creative and exciting event was produced (see Figure 5). One idea that developed was to have contributions from other sectors, with Highways England, Electricity North West and Heathrow Airport all invited to 
Figure 5: The benefits of co-creating events to communicate research

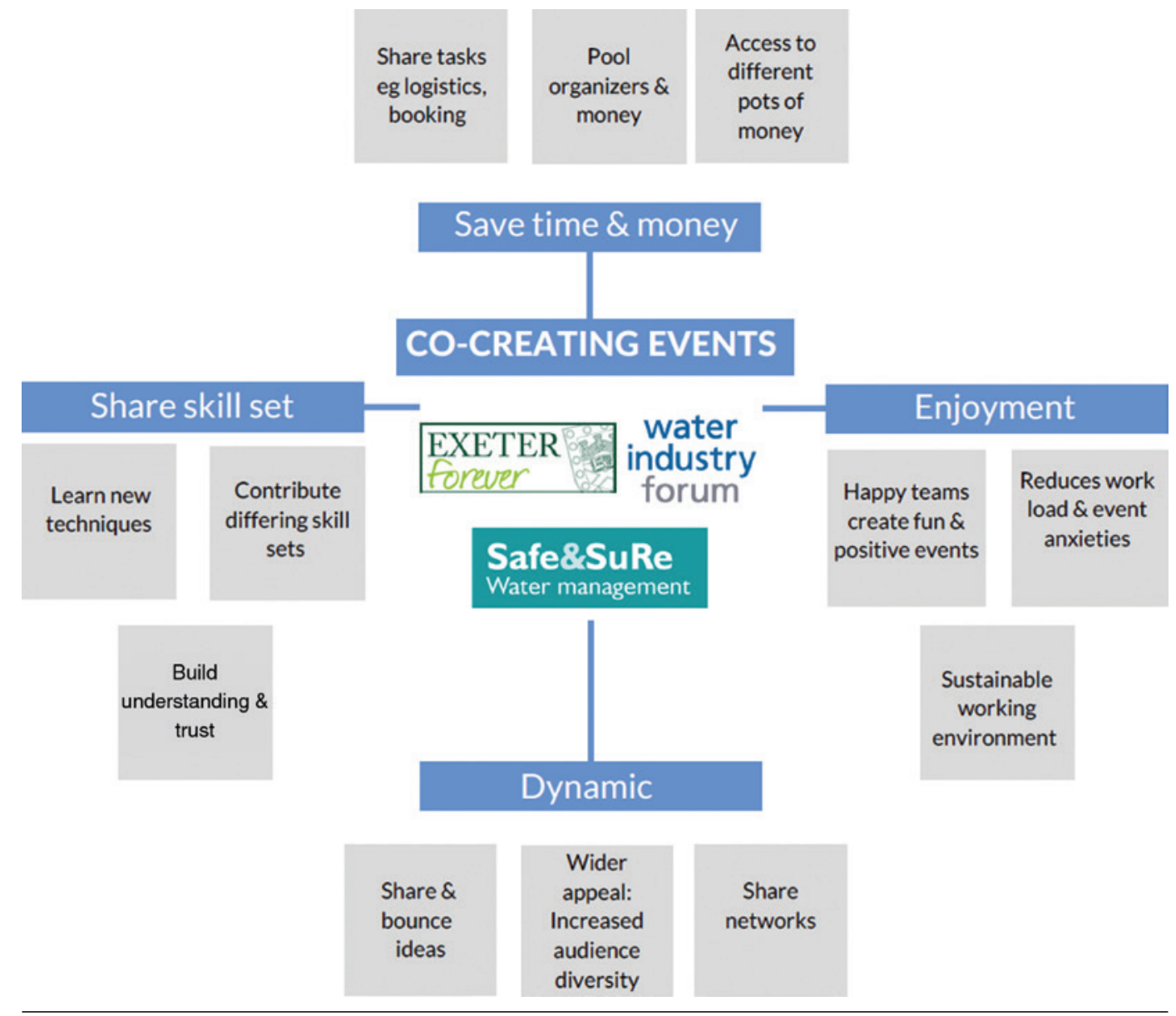

contribute on the topic of resilience. The symposium was classed as a success, with over 45 people attending, including a mix of water companies, consultancies and government sectors. Out of the 19 who filled out the event evaluation form, 14 classed the event as 'very good' or 'excellent'.

Both events were found to be beneficial to researchers as they were a space to meet and talk with practitioners in the water sector, to find out the current concerns of industry, and to discuss the potential applicability of their research.

\section{Discussion}

Since the early 1990s, universities and funders have encouraged researchers to be more relevant to society by taking up 'public engagement' (Burchell et al., 2017). However, there has been less of a focus for researchers to work with industry - for instance, 'industry' engagement barely features in the 'Vitae Researcher Development Framework' (Vitae, 2011), and not at all in its public engagement lens (Vitae, 2013). A study published in 2015 by the Wellcome Trust reported that researchers in STEM subjects (this includes water engineering) were less involved in public engagement compared to other disciplines, with a focus on one-way communication to the public (Consortium of UK Public Funders of Research, 2015; Burchell et al., 2017). This paper demonstrates that STEM researchers do have the skill set to conduct successful twoway engagement and co-production, but engagement is focused on industry, rather than the general public. 
University-industry collaboration has a long-standing relationship, with a history dating back to the 1800s (Borrell-Damian, 2009). This is far more established compared to societal engagement, which has been the subject of attention from universities and funders for only the past thirty years (Burchell et al., 2017). As this paper shows, there is much learning to be shared across the different forms of engagement. The following section embeds Safe \& SuRe learnings within the literature and explicitly answers the three questions posed at the beginning of the paper.

\section{How do academics and industry benefit from working together?}

The real benefit of Established Career Fellowships, such as the Safe \& SuRe project, is that they provide sufficient funds to support co-production over a long period of time. This builds the confidence of mid-career academics to engage with actors beyond academia, and provides informal development opportunities in engagement for early career researchers. Research shows that trust tends to increase with frequent communication (De Wit-de Vries et al., 2019), and, as trust builds, it gives people confidence in sharing information (Plewa et al., 2013; Steinmo, 2015). Engaging over a long period of time also means that the knowledge and/or technology is more likely to fit industry needs (Lemos and Morehouse, 2005; Lemos et al., 2018).

Co-producing research with the steering group meant that researchers had to explain unstated assumptions, and to think about the 'bigger picture' of their research and how it can be used to solve current problems. Involving stakeholders throughout the whole process helped build credibility for findings and outputs. Halofsky et al. (2011) define this process as 'live peer review', where research is constantly being reviewed, instead of the traditional format of academic peer review, where research is assessed at the end of the project. This process improves the legitimacy, credibility and relevance of the science (Johnson, 2011; Ferguson et al., 2018).

The value of co-disseminating results and information is often viewed as second to co-production, instead of viewing it as an important part of the engagement process (Djenontin and Meadow, 2018). The Safe \& SuRe project highlights how collaboration across university departments and institutes should be encouraged to improve organizational efficiency and to aid internal networking and collaborations. Relationships with industry need to stretch beyond the individual projects into sustained working partnerships, with networking and events as a method to do this. Co-disseminating with stakeholders helps to maintain connections and engage new networks, and can help lead to new research questions (Mauser et al., 2013). An example of this is when the Safe \& SuRe PI met Scottish Water engineers at a conference and the idea of co-developing research from Safe \& SuRe was sparked.

\section{What are the challenges, and learnings, from Safe \& SuRe working with industry?}

There are cultural differences between academia and industry that can affect the process of collaborative research and be frustrating for both parties (Djenontin and Meadow, 2018). Academics are judged by the number of publications and grants, which reduces the amount of time they have to engage with stakeholders and creates a difference in the pace of work (Cvitanovic et al., 2016). During Safe \& SuRe, frequent communication helped both sides understand the different pressures, and ensured that industry did not feel excluded from the scientific process. However, the steering group highlighted that more frequent meetings, and a chance for industry to present their work, would have improved the process. One steering group 
member thought that some aspects of the project were behind industry, which also suggests that researchers should include grey literature alongside their academic sources.

Co-production can be taxing, time consuming and intimidating for everyone involved (Lemos et al., 2018). It is, therefore, not unusual for academics to work with the same stakeholders, such as a steering group (Porter and Dessai, 2017; Lemos et al., 2018). Although in the short term it is easier for researchers to work with the same stakeholders, in the long term it can limit the success of the project and create fatigue in the stakeholders (Newton and Elliott, 2016). For this reason, researchers in Safe \& SuRe were actively encouraged to network and make new connections with industry. The Safe \& SuRe PI made it 'his business' to speak at, chair and attend industry-led events, and he motivated researchers to do the same. This top-down encouragement helps to create a research culture that values engagement and co-production.

\section{How could the Safe \& SuRe co-production be improved?}

Some of the researchers highlighted that the outputs of the project could have been very different if the steering group had been more diverse. The Safe \& SuRe steering group were chosen as trusted and established contacts of the PI and co-Pls from the water industry, but there was no representation from NGOs or community groups. Jensen et al. (2008) argue that engaging with people from diverse backgrounds can improve practices in science, as well as benefiting individual researchers by improving their academic work. Where research is being developed to inform decisions relating to communities, then we suggest they are included from project inception. It is also important to have researchers with the appropriate skill set, such as behaviour social scientists or sociologists, to lead or advise on the process.

Evaluating knowledge co-production is vital as it helps to understand which outcomes of the project are attributed to stakeholder engagement and how the practice can be improved (Lemos et al., 2018; Fulgenzi et al., 2020). Although this paper is a positive example of reviewing the co-production process, a limitation was not having an evaluation process locked into place at the beginning of the project. Setting metrics and defining success at the beginning of a collaboration can ensure that progress can be appropriately reviewed, evaluated and improved. This process would have helped monitor and align everyone's expectations, which could have helped researchers to effectively manage the academic and industry expectations.

\section{Conclusion}

Five years is unusually long for funded research, and even more unusual for funded public engagement. The Safe \& SuRe project has highlighted the many benefits of this long-term co-production to enable knowledge to be used directly in industry and government decision making, while also having wider impacts on the personal development of researchers. The steering group used for universityindustry collaboration provided a forum for mutual learning that goes beyond the one-way communication often reported by STEM academics when asked about public engagement. The paper also highlights the importance of co-disseminating research with industry; the value of dissemination and networking should not be forgotten as important building blocks for future collaborations. In a landscape where universities are encouraged to be more relevant to society by taking up 'public engagement', this paper offers learning from the thriving field of universityindustry collaborations. 


\section{Acknowledgements}

The Safe \& SuRe project was funded by the UK Engineering and Physical Sciences Research Council (EP/K006924/1).

\section{Notes on the contributors}

Kate Baker is a postdoctoral research fellow in the Centre for Water Systems at the University of Exeter and led the co-production strategy and activities of the Safe \& SuRe project from 2017. She is co-founder of Agile Rabbit (www.agile-rabbit.com), an organization that helps academics engage their work with the public through events and podcasts, and in 2019 she became a community engagement fellow at the Center for Scientific Collaboration and Community Engagement (www.cscce.org).

Sarah Ward is Associate Professor of Environmental Hazards and Community Resilience at the University of the West of England, Bristol with twenty years' experience in the water sector. She is a chartered water and environmental manager, a chartered environmentalist and a fellow of the Higher Education Academy. Associate Professor Ward was a co-investigator on the fellowship: she led two work packages focusing on community and organizational resilience, and initially led the engagement and knowledge exchange activities.

Briony Turner manages the Space4Climate group, hosted by the National Centre for Earth Observation. She specializes in academic-public-private knowledge exchange, is on the London Climate Change Partnership, is Vice-Chair of the CIBSE Resilient Cities group and co-founded Mesh (http://meshclimate.net/), a network for the UK climate services community. She previously worked for the UK Climate Impacts Programme and was awarded ESRC Impact Champion 2016.

James Webber is a research impact fellow at the Centre for Water Systems. His work on the Safe \& SuRe project was focused on developing, engaging and applying new research with industry and government partners. Prior to joining the project, he worked as an engineering consultant for a multinational company.

Chris Sweetapple is a research fellow at the University of Exeter, where he works with the Centre for Water Systems. His research is focused on improving both resilience and sustainability in the water sector, and he has developed methodologies and modelling tools for evaluating the resilience of a variety of water systems under the Safe \& SuRe project.

Peter Drake is CEO (and joint founder) of the Water Industry Forum - an independent, not-for-profit stakeholder forum that facilitates collaboration across the UK water sector around the sector's many challenges. Peter is a chartered civil engineer and chartered water and environment manager with wide experience of the water industry, including roles with an engineering consultancy, the Environment Agency and a water company.

David Thomas works as a strategic planner for Scottish Water and leads the wastewater resilience strategy. His work focuses on understanding and enhancing the resilience of wastewater assets and treatment processes to acute and chronic stresses/hazards. Prior to this role, he worked as a water resource hydrologist for both Scottish Water and the Environment Agency with a focus upon resilience to drought. 
Peter Melville-Shreeve is a lecturer in engineering and entrepreneurship. He has worked for over a decade in research and commercial roles relating to water demand and stormwater management. He has developed a spin-out company that harnesses data from internet of things devices to improve the efficiency of our water infrastructure systems.

Guangtao Fu is Professor of Water Intelligence at the Centre for Water Systems. He is Royal Society Industry Fellow and Turing Fellow, and his research focuses on developing and applying new computer models, data analytics and artificial intelligence to tackle challenges in water supply, urban flooding, stormwater and wastewater management. He was a co-investigator on the fellowship with a focus on stormwater and wastewater systems.

Stephanie Cherington-Rimmell is a senior development manager in the Global Advancement team at the University of Exeter. She has over ten years' experience in the philanthropy sector, and a key part of her role is to engage audiences with scientific research, developing relationships and securing philanthropic funds from individuals and organizations.

Raziyeh Farmani is Associate Professor of Water Engineering and Industrial Fellow of the Royal Academy of Engineering at the Centre for Water Systems. She specializes in urban water systems modelling, asset management, water resources management, many-objective optimization, uncertainty and risk assessment, and decision aid. She was a co-investigator on the Safe \& SuRe project, with a main focus on the resilience and sustainability of urban water systems.

David Butler is Professor of Water Engineering at the University of Exeter, with over 35 years' experience in the water sector. He is a chartered civil engineer and a fellow of the Royal Academy of Engineering, the Institution of Civil Engineers, the Chartered Institution of Water and Environmental Management and the International Water Association. Professor Butler was the Principal Investigator and lead on the Safe \& SuRe fellowship.

\section{References}

Bjerregaard, T. (2010) 'Industry and academia in convergence: Micro-institutional dimensions of R\&D collaboration'. Technovation, 30 (2), 100-8. Online. https://doi.org/10.1016/j. technovation.2009.11.002

Boardman, P.C. and Ponomariov, B.L. (2009) 'University researchers working with private companies'. Technovation, 29 (2), 142-53. Online. https://doi.org/10.1016/j.technovation. 2008.03.008

Borrell-Damian, L. (2009) University-Industry Partnerships for Enhancing Knowledge Exchange. Brussels: European University Association.

Burchell, K., Sheppard, C. and Chambers, J. (2017) 'A "work in progress"? UK researchers and participation in public engagement'. Research for All, 1 (1), 198-224. Online. https://doi.org/10.18546/RFA.01.1.16

Cherney, A. (2015) 'Academic-industry collaborations and knowledge co-production in the social sciences'. Journal of Sociology, 51 (4), 1003-16. Online. https://doi.org/10.1177/ 1440783313492237

Consortium of UK Public Funders of Research (2015) Factors Affecting Public Engagement by Researchers: Reflections on the changing landscape of public engagement by researchers in the UK. London: Wellcome Trust. Online. https://wellcome.ac.uk/sites/default/files/wtp060034.pdf (accessed 5 January 2020). 
Cvitanovic, C., McDonald, J. and Hobday, A.J. (2016) 'From science to action: Principles for undertaking environmental research that enables knowledge exchange and evidence-based decision-making'. Journal of Environmental Management, 183 (3), 864-74. Online. https://doi.org/10.1016/j.jenvman.2016.09.038

De Wit-de Vries, E., Dolfsma, W.A., Van der Windt, H.J. and Gerkema, M.P. (2019) 'Knowledge transfer in university-industry research partnerships: A review'. Journal of Technology Transfer, 44, 1236-55. Online. https://doi.org/10.1007/s10961-018-9660-x

Dewulf, A., Craps, M., Bouwen, R., Taillieu, T. and Pahl-Wostl, C. (2005) 'Integrated management of natural resources: Dealing with ambiguous issues, multiple actors and diverging frames'. Water Science and Technology, 52 (6), 115-24. Online. https://doi.org/10.2166/wst.2005.0159

Djenontin, I.N.S. and Meadow, A.M. (2018) 'The art of co-production of knowledge in environmental sciences and management: Lessons from international practice'. Environmental Management, 61 (6), 885-903. Online. https://doi.org/10.1007/s00267-018-1028-3

Fenwick, T. (2016) Professional Responsibility and Professionalism: A sociomaterial examination. London: Routledge.

Ferguson, L., Chan, S., Santelmann, M.V. and Tilt, B. (2018) 'Transdisciplinary research in water sustainability: What's in it for an engaged researcher-stakeholder community?'. Water Alternatives, 11 (1), 1-18.

Fulgenzi, A., Brouwer, S., Baker, K. and Frijns, J. (2020) 'Communities of practice at the center of circular water solutions'. WIREs Water, Article e21450, 1-15. Online. https://doi.org/10.1002/wat2.1450

Gertner, D., Roberts, J. and Charles, D. (2011) 'University-industry collaboration: A CoPs approach to KTPs'. Journal of Knowledge Management, 15 (4), 625-47. Online. https://doi.org/10.1108/13673271111151992

Halofsky, J.E., Peterson, D.L., Furniss, M.J., Joyce, L.A., Millar, C.I. and Neilson, R.P. (2011) 'Workshop approach for developing climate change adaptation strategies and actions for natural resource management agencies in the United States'. Journal of Forestry, 109 (4), $219-25$.

Harding, S. (2006) Science and Social Inequality: Feminist and postcolonial issues. Urbana: University of Illinois Press.

Jasanoff, S. and Wynne, B. (1998) 'Science and decision making'. In Rayner, S. and Malone, E.L. (eds) Human Choice and Climate Change, Vol 1: The Societal Framework. Columbus, OH: Battelle Press, 1-87.

Jensen, P., Rouquier, J.-B., Kreimer, P. and Croissant, Y. (2008) 'Scientists who engage with society perform better academically'. Science and Public Policy, 35 (7), 527-41. Online. https://doi.org/10.3152/030234208X329130

Johnson, T.R. (2011) 'Fishermen, scientists, and boundary spanners: Cooperative research in the US Illex squid fishery'. Society and Natural Resources, 24 (3), 242-55. Online. https://doi.org/10.1080/08941920802545800

Lemos, M.C., Arnott, J.C., Ardoin, N.M., Baja, K., Bednarek, A.T., Dewulf, A., Fieseler, C., Goodrich, K.A., Jagannathan, K., Klenk, N., Mach, K.J., Meadow, A.M., Meyer, R., Moss, R., Nichols, L., Sjostrom, K.D., Stults, M., Turnhout, E., Vaughan, C., Wong-Parodi, G. and Wyborn, C. (2018) 'To co-produce or not to co-produce'. Nature Sustainability, 1 (12), 722-4. Online. https://doi.org/10.1038/s41893-018-0191-0

Lemos, M.C. and Morehouse, B.J. (2005) 'The co-production of science and policy in integrated climate assessments'. Global Environmental Change, 15 (1), 57-68. Online. https://doi.org/10.1016/j.gloenvcha.2004.09.004

Mader, M., Mader, C., Zimmermann, F.M., Görsdorf-Lechevin, E. and Diethart, M. (2013) 'Monitoring networking between higher education institutions and regional actors'. Journal of Cleaner Production, 49, 105-13. Online. https://doi.org/10.1016/j.jclepro.2012.07.046

Mauser, W., Klepper, G., Rice, M., Schmalzbauer, B.S., Hackmann, H., Leemans, R. and Moore, H. (2013) 'Transdisciplinary global change research: The co-creation of knowledge for sustainability'. Current Opinion in Environmental Sustainability, 5 (3-4), 420-31. Online. https://doi.org/10.1016/j.cosust.2013.07.001

Meadow, A.M., Ferguson, D.B., Guido, Z., Horangic, A., Owen, G. and Wall, T. (2015) 'Moving toward the deliberate coproduction of climate science knowledge'. Weather, Climate, and Society, 7 (2), 179-91. Online. https://doi.org/10.1175/WCAS-D-14-00050.1

Newton, A. and Elliott, M. (2016) 'A typology of stakeholders and guidelines for engagement in transdisciplinary, participatory processes'. Frontiers in Marine Science, 3, Article 230, 1-13. Online. https://doi.org/10.3389/fmars.2016.00230

Ofwat (2017) Resilience in the Round: Building resilience for the future. Birmingham: Ofwat. Online. www. ofwat.gov.uk/wp-content/uploads/2017/09/Resilience-in-the-Round-report.pdf (accessed 28 April 2020). 
Phillipson, J., Lowe, P., Proctor, A. and Ruto, E. (2012) 'Stakeholder engagement and knowledge exchange in environmental research'. Journal of Environmental Management, 95 (1), 56-65. Online. https://doi.org/10.1016/j.jenvman.2011.10.005

Plewa, C., Korf, N., Johnson, C., Macpherson, G., Baaken, T. and Rampersad, G.C. (2013) 'The evolution of university-industry linkages: A framework'. Journal of Engineering and Technology Management, 30 (1), 21-44. Online. https://doi.org/10.1016/j.jengtecman.2012.11.005

Porter, J.J. and Dessai, S. (2017) 'Mini-me: Why do climate scientists misunderstand users and their needs?'. Environmental Science and Policy, 77, 9-14. Online. https://doi.org/10.1016/j. envsci.2017.07.004

Sol, J., Beers, P.J. and Wals, A.E. (2013) 'Social learning in regional innovation networks: Trust, commitment and reframing as emergent properties of interaction'. Journal of Cleaner Production, 49, 35-43.

Steinmo, M. (2015) 'Collaboration for innovation: A case study on how social capital mitigates collaborative challenges in university-industry research alliances'. Industry and Innovation, 22 (7), 597-624. Online. https://doi.org/10.1080/13662716.2015.1105127

Trencher, G., Bai, X., Evans, J., McCormick, K. and Yarime, M. (2014) 'University partnerships for codesigning and co-producing urban sustainability'. Global Environmental Change, 28, 153-65. Online. https://doi.org/10.1016/j.gloenvcha.2014.06.009

UKRI (UK Research and Innovation) (2020) 'Pathways to Impact: Impact core to the UK Research and Innovation application process'. London: UKRI. Online. www.ukri.org/news/pathways-to-impactimpact-core-to-the-uk-research-and-innovation-application-process/ (accessed 30 April 2020).

Vitae (2011) 'Vitae Researcher Development Framework (RDF)'. London: Vitae. Online. www.vitae. ac.uk/vitae-publications/rdf-related/researcher-development-framework-rdf-vitae.pdf/view (accessed 15 May 2020).

Vitae (2013) 'Public Engagement Lens on the Vitae Researcher Development Framework'. London: Vitae. Online. www.vitae.ac.uk/vitae-publications/rdf-related/public-engagement-lens-on-thevitae-researcher-development-framework-rdf-apr-2013.pdf (accessed 15 May 2020).

Wall, T.U., Meadow, A.M. and Horganic, A. (2017) 'Developing evaluation indicators to improve the process of coproducing usable climate science'. Weather, Climate, and Society, 9 (1), 95-107. Online. https://doi.org/10.1175/WCAS-D-16-0008.1

Ward, S., Butler, D., Adams, R., O'Callaghan, S., Warren, N., Wickett, M., Swire, H., De Mora, S. and Uden, C. (2018) 'Developing university-society partnerships with a focus on climate change impact research using the "business assist" model'. Research for All, 2 (1), 163-74. Online. https://doi.org/10.18546/RFA.02.1.14

Webber, J.L., Booth, G., Gunasekara, R., Fu, G. and Butler, D. (2019) 'Validating a rapid assessment framework for screening surface water flood risk'. Water and Environment Journal, 33 (3), 427-42. Online. https://doi.org/10.1111/wej.12415 